\title{
Introduction of Surface Loops as a Tool for Encapsulin Functionalization
}

\author{
Sandra Michel-Souzy,* Naomi M. Hamelmann, Sara Zarzuela-Pura, Jos M. J. Paulusse, \\ and Jeroen J. L. M. Cornelissen*
}

Cite This: Biomacromolecules 2021, 22, 5234-5242

Read Online

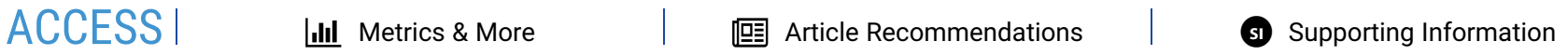

ABSTRACT: Encapsulin-based protein cages are nanoparticles with potential biomedical applications, such as targeted drug delivery or imaging. These particles are biocompatible and can be produced in bacteria, allowing large-scale production and protein engineering. In order to use these bacterial nanocages in different applications, it is important to further explore their surface modification and optimize their production. In this study, we design and show new surface modifications of Thermotoga maritima ( $\mathrm{Tm})$ and Brevibacterium linens ( $\mathrm{Bl}$ ) encapsulins. Two new loops on the Tm encapsulin with a His-tag insertion after residue 64 and residue 127 and the modification of the $\mathrm{C}$-terminus on the $\mathrm{Bl}$ encapsulin are reported. The multimodification of the Tm encapsulin enables up to 240 functionalities on the cage surface, resulting from four potential modifications per protein subunit. We further report an improved production protocol giving a better stability and good production yield of the cages. Finally, we tested the stability of different encapsulin variants over a year, and the results show a difference in stability arising from the tag insertion position. These first insights in the structure-property relationship of encapsulins, with respect to the position of a functional loop, allow for further study of the use of these protein nanocages in biomedical applications.

\section{INTRODUCTION}

The constant development of biomedical tools for drug targeting, drug delivery, vaccines, or imaging requires efficient biocompatible carriers, accepted by the host, with an adequate response and with no/low toxicity. ${ }^{1}$ Consequently, nanoparticles have been built, such as liposomes, ${ }^{2}$ polymers, ${ }^{3}$ micelles, ${ }^{4}$ or protein cages. ${ }^{5}$ Previous studies on protein cages report on a variety of different applications, such as targeted drug delivery, gene reporting, and vaccines. ${ }^{6-8}$ Protein cages are welldefined monodisperse, hollow, spherical structures, in the size range of $1-100 \mathrm{~nm}$, which are generally biocompatible. ${ }^{9-11}$ Among the variety of protein cages, our work focuses on encapsulins that are found in bacteria and archaea ${ }^{12}$ and may have viral origin shared with the capsid proteins of tailed bacteriophages. ${ }^{13-15}$ The advantages of bacterial protein cages are that they can be easily engineered and produced and they self-assemble in bacteria. ${ }^{16}$ Furthermore, encapsulins can not only encapsulate endogenous cargo but also exogenous cargo, thanks to an extension sequence in the C-terminus. ${ }^{15,17}$ The accumulation of all these properties makes encapsulins promising candidates for developing (drug) delivery carriers, imaging and diagnosis agents, or bionanoreactors. In our studies, we focus on the encapsulins of two species: Thermotoga maritima $(\mathrm{Tm})$ and Brevibacterium linens (Bl). The goal here is to perform an in-depth investigation to further extend the possibilities for surface modification in order to introduce functionalities and improve stability for the Tm encapsulin (Tmenc) and $\mathrm{Bl}$ encapsulin (Blenc). Additionally, we aim to increase the purification yield of encapsulins for large-scale usage.

The encapsulins, in this study, are protein cages composed of 60 monomers assembled in a $T=1$ symmetry (which is an icosahedron composed of 60 asymmetric protein building blocks). ${ }^{15,18}$ The encapsulin surface can be modified either chemically or genetically. The latter allows insertion of a desired peptide (e.g., a targeting peptide) with high control over both the amount and the position in the cage. This peptide insertion at a single site of the protein monomer will lead to 60 functional groups on the nanocage surface. The design and fine tuning of modifiable locations, without disturbing the cage structure,

Received: September 3, 2021

Revised: October 15, 2021

Published: November 8, 2021 
allows for versatile surface modifications, which is crucial for a large variety of applications.

So far, seven genetically modified sites have been reported on encapsulins, which were all developed on the Tmenc. ${ }^{19-23}$ The monomeric protein of Tmenc consists of three domains; P, E, and $\mathrm{A}$ (Figure $1 \mathrm{~B}$ ). The reported modifications are located on

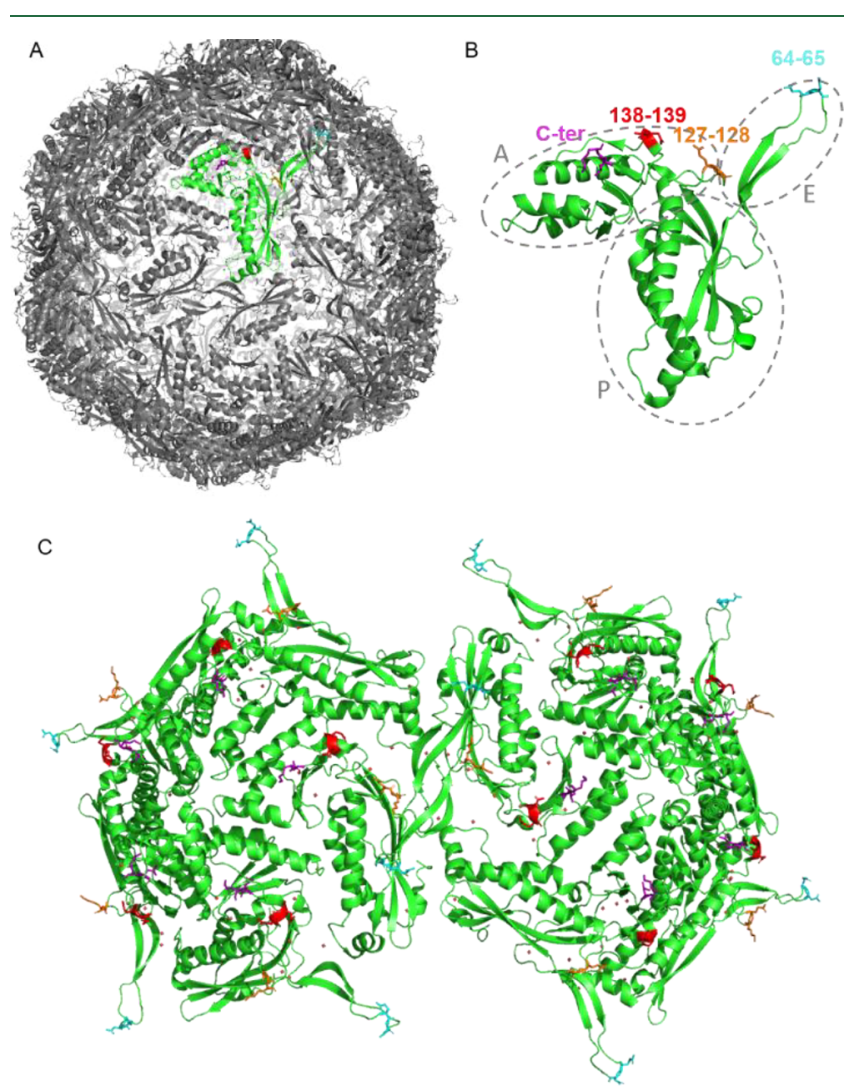

Figure 1. Structure of the Tm encapsulin (Sutter et al. ${ }^{15}$ ) highlighting loop 64 (cyan) with glutamate 64 and asparagine 65. Loop 127 (orange) with glutamate 127 and lysine 128. Loop 138 (red) with glutamate 138 and 139 . The C-terminus is in purple with the two terminal residues being lysine and phenylalanine. (A) Entire cage is shown with one monomer in green. (B) One monomer with the positions of the different exposed loops. (C) Zoom in of two pentamers, to show the different positions of the loops on the surface of the encapsulin.

the $\mathrm{N}$-terminus and in loop positions $42-43$ (which are in the $\mathrm{P}$ domain), 138-139 and C-terminus (A-domain), and loop positions 57-58, 60-61, and 71-72 (E-domain). Moreover, among those seven positions, five are exposed on the surface of the $\mathrm{Tm}$ encapsulin, which are located in the A- and Edomains. ${ }^{19,23}$ For these five surface exposed positions, results from Moon et al. suggest that the C-terminus is less accessible, as the variant with six histidines inserted at the $\mathrm{C}$-terminus could not be purified on a nickel affinity column. ${ }^{19}$ Regarding modifications in the E-domain, the modification between the residues 71-72 leads to a disruption of the cage, while modifications after residues 57 and 60 are mostly insoluble with low purification yield. ${ }^{23}$ Clearly, there is a need for further investigations about alternative loops that may be engineered on the surface of Tmenc and by homology on Blenc. In this study, we reveal two new positions on the surface of Tmenc where a peptide can be inserted, and we extend the C-terminus with a peptide of additional 10 amino acids. Furthermore, an improved protocol for encapsulin purification is described. Noticeably, our study demonstrates that the sequence homology between different encapsulin species does not exactly reflect the structural homology, and we show the possibility of using the C-terminus as an engineerable position on the surface of Blenc.

\section{MATERIALS AND METHODS}

Bacterial Strains and Plasmids. Bacterial strains and plasmids used in this study are listed in Table 1.

DNA Manipulation. Plasmid preparation, DNA purification, and polymerase chain reaction (PCR) product purification were performed using the appropriate Macherey Nagel kits. Restriction enzymes, DNA polymerase, and other molecular biology reagents were purchased from New England Biolabs. High fidelity polymerase Q5 (NEB) was used for PCR amplification. The sequences of all used oligonucleotides (purchased from Eurofins Genomics) are listed in Table 2. To construct the expression plasmids for encapsulin genes, the encapsulin genes were PCR-amplified using corresponding primers and cloned into $\mathrm{pCDFDuet}$ or pRSFDuet vectors (Novagen) using the sequenceand ligation-independent cloning (SLIC) method $^{24}$ between NdeIEcoRV (MCS2) restriction sites. The sfGFP gene was cloned into the pETDuet vector (Novagen) using the SLIC method between NcoI-SalI (MCS1). The sequences of all plasmids were verified using the sequencing service of Eurofins Genomics.

Protein Production and Purification. Competent cells of E. coli Rosetta strain were transformed with $\mathrm{pCDF}$ or pRSF-enc variants or cotransformed with pRSF-enc variants and $\mathrm{pET}$-sfGFPE $\mathrm{flp}_{\mathrm{fl}}$. The bacteria were grown until $0.5 \mathrm{OD}$ at $\lambda=600 \mathrm{~nm}$ at $37{ }^{\circ} \mathrm{C}$ in the $\mathrm{LB}$ medium with an appropriate antibiotic (streptomycin $30 \mu \mathrm{g} / \mathrm{mL}$, kanamycin $30 \mu \mathrm{g} / \mathrm{mL}$, and/or ampicillin $50 \mu \mathrm{g} / \mathrm{mL}$ ). The expression of the different encapsulin genes was induced with $1 \mathrm{mM} \mathrm{IPTG}$ for $12 \mathrm{~h}$ at $25{ }^{\circ} \mathrm{C}$. The bacteria were collected by centrifugation and lysed by sonication $(2 \times 1 \mathrm{~min})$ in $50 \mathrm{mM}$ Hepes buffer $(\mathrm{pH} 8,150 \mathrm{mM} \mathrm{NaCl}, 1$ $\mathrm{mM}$ EDTA, $20 \mathrm{mM} \mathrm{MgCl} 2,1$ protease inhibitor tablet $/ 7 \mathrm{~mL}$ (cOmplete), $0.5 \mathrm{mg} / \mathrm{mL}$ lysosyme, $20 \mu \mathrm{g} / \mathrm{mL}$ DNAse, $30 \mathrm{mM}$ imidazole, and $15 \mathrm{mM}$ beta-mercaptoethanol $(\beta \mathrm{me}))$. The lysate was cleared by ultracentrifugation $(20,000 \times g)$ to remove cell debris. Cleared lysates containing encapsulin histidine variants were each loaded onto separate $3 \mathrm{~mL}$ Ni-NTA-functionalized agarose beads (Protino Ni-NTA Agarose) in Biorad gravity columns for $1 \mathrm{~h}$. The immobilized proteins were washed using washing buffer $(50 \mathrm{mM}$ Hepes $\mathrm{pH} 8,150 \mathrm{mM} \mathrm{NaCl}, 15 \mathrm{mM} \beta \mathrm{me}$, and $30 \mathrm{mM}$ imidazole) and eluted in elution buffer ( $50 \mathrm{mM}$ Hepes $\mathrm{pH} 8,150 \mathrm{mM} \mathrm{NaCl}, 15 \mathrm{mM} \beta \mathrm{me}$, and $500 \mathrm{mM}$ imidazole). The buffers for the purification of the strep encapsulin variant did not contain imidazole. The cleared lysatecontaining encapsulin strep variants were loaded on a StrepTrap Hp 5 $\mathrm{mL}$ column (Cytiva) using a BioRad NGC FPLC. The immobilized proteins were eluted in elution buffer $(50 \mathrm{mM}$ Hepes $\mathrm{pH} 8,150 \mathrm{mM}$ $\mathrm{NaCl}, 15 \mathrm{mM} \beta \mathrm{me}$, and $2,5 \mathrm{mM}$ desthiobiotine).

The proteins were concentrated using Amicon Ultra Centrifugal filters (Millipore, 100-kDa cut-off) and purified using size exclusion chromatography on a Superose $610 / 300$ increase column preequilibrated with $50 \mathrm{mM}$ Hepes $\mathrm{pH} 8$, containing $150 \mathrm{mM} \mathrm{NaCl}$ and $15 \mathrm{mM} \beta \mathrm{me}$.

Sodium Dodecyl Sulfate-Polyacrylamide Gel Electrophoresis (SDS-PAGE) and Immuno Detection. Proteins from different purification steps were separated by electrophoresis on $15 \%$ polyacrylamide gels and stained using Coomassie brilliant blue. Proteins from bacterial extracts were separated by electrophoresis on $15 \%$ polyacrylamide gels and transferred onto nitrocellulose membranes using a wet blotting apparatus (BioRad). Membranes were blocked with 5\% milk in PBST (Phosphate buffer saline; 0.05\% Tween 20) and incubated with monoclonal mouse anti-His antibody (Penta His, Qiagen, dilution 1:1000) according to the manufacturers' instructions. This was followed by two $10 \mathrm{~min}$ washes and a $1 \mathrm{~h}$ incubation in peroxidase-labeled antimouse antibody (1:2000, Sigma). Membranes were developed by homemade enhanced chemiluminescence and scanned using FluorChem $\mathrm{M}$ hardware (Proteinsimple). 
Table 1. Bacterial Strain and Plasmids Used in This Study

\begin{tabular}{|c|c|c|}
\hline strain and plasmids & genotype/characteristics & origin \\
\hline \multicolumn{3}{|l|}{ E. coli } \\
\hline Rosetta(DE3) & F-ompT hsdSB(rB-mB-) gal dcm (DE3) pRARE (CamR) & Novagen \\
\hline NovaBlue & endA1 hsdR17 (rK12- mK12+) supE44 thi-1 recA1 gyrA96 relA1 lac $F^{\prime}[p r o A+B+$ lacIqZDM15::Tn10] (TetR) & Novagen \\
\hline \multicolumn{3}{|l|}{ plasmids } \\
\hline pCDFDuet-1 & $\mathrm{Sm}^{\mathrm{R}}, 2 \mathrm{MCS}, \mathrm{P}_{\mathrm{T} 7}$, Ori CDF & Novagen \\
\hline pETDuet-1 & $\mathrm{Ap}^{\mathrm{R}}, 2 \mathrm{MCS}, \mathrm{P}_{\mathrm{T} 7}$, Ori f1 & Novagen \\
\hline pRSFDuet & $\mathrm{Km}^{\mathrm{R}}, 2 \mathrm{MCS}, \mathrm{P}_{\mathrm{T} 7}$, Ori RSF 1030 & Novagen \\
\hline pET21a-Blenc-dyp & pET21a carrying bl encapsulin and $d y p$ genes & Putri et al. ${ }^{18}$ \\
\hline $\begin{array}{l}\text { pET21a-Tmenc- } \\
\text { mTFP }\end{array}$ & pET21a carrying tm encapsulin and $m$ TFP genes & $\begin{array}{l}\text { laboratory } \\
\text { collection }\end{array}$ \\
\hline pCDF-Tm64H $\mathrm{H}_{10}$ & pCDFDuet carrying tm encapsulin gene with His-tag insertion in position 64 cloned in MCS 2 & this study \\
\hline pCDF-Tm $127 \mathrm{H}_{10}$ & pCDFDuet carrying tm encapsulin gene with His-tag insertion in position 127 cloned in MCS 2 & this study \\
\hline pCDF-Tm $138 \mathrm{H}_{10}$ & pCDFDuet carrying tm encapsulin gene with His-tag insertion in position 138 cloned in MCS 2 & this study \\
\hline pCDF-TmCtH 10 & pCDFDuet carrying tm encapsulin gene with His-tag insertion in the C-terminal position cloned in MCS 2 & this study \\
\hline pCDF-Bl61H 10 & pCDFDuet carrying bl encapsulin gene with His-tag insertion in position 61 cloned in MCS 2 & this study \\
\hline pCDF-Bl124H $\mathrm{H}_{10}$ & pCDFDuet carrying $b l$ encapsulin gene with His-tag insertion in position 124 cloned in MCS 2 & this study \\
\hline pCDF-Bl135H $\mathrm{H}_{10}$ & pCDFDuet carrying bl encapsulin gene with His-tag insertion in position 135 cloned in MCS 2 & this study \\
\hline pCDF-BlCtH ${ }_{10}$ & pCDFDuet carrying $b l$ encapsulin gene with His-tag insertion in the C-terminal position cloned in MCS 2 & this study \\
\hline pRSF-Tm127strep & pRSFDuet carrying tm encapsulin gene with strep tag II insertion in position 127 cloned in MCS 2 & this study \\
\hline $\begin{array}{l}\text { pRSF-Tm127PepC7- } \\
\text { Cstrep }\end{array}$ & $\begin{array}{l}\text { pRSFDuet carrying tm encapsulin gene with PepC7 peptide insertion in position } 127 \text { and strep tag II insertion in the C- } \\
\text { terminal position cloned in MCS } 2\end{array}$ & this study \\
\hline pET-sfGFPE $E_{\text {flp }}$ & pETDuet carrying sfGFP gene fused with the C-terminal sequence of ferredoxin-like protein cloned in MCS 1 & this study \\
\hline
\end{tabular}

Table 2. Oligonucleotides Used in This Study ${ }^{a}$

\begin{tabular}{|c|c|c|}
\hline oligo & sequence $5^{\prime} \rightarrow 3^{\prime}$ & characteristics \\
\hline OSMS-1 & AAGGAGATATACATATGAATAACCTCTATCGCGAGCT & $\begin{array}{l}\text { PCR Blenc forward for NdeI site in pDuet } \\
\text { MCS2 }\end{array}$ \\
\hline OSMS-2 & $\begin{array}{l}\text { GCGTGGCCGGCCGATATCTCAATGATGATGGTGATGGTGATGGTGATGAT } \\
\text { GGAGGCTCAAAGGCACACT }\end{array}$ & $\begin{array}{l}\text { PCR BlencH10 reverse for EcoRV site in } \\
\text { pDuet MCS2 }\end{array}$ \\
\hline OSMS-7 & GCGTGGCCGGCCGATATCTCAGAGGCTCAAAGGCACACT & $\begin{array}{l}\text { PCR Blenc reverse for EcoRV site in pDuet } \\
\text { MCS2 }\end{array}$ \\
\hline OSMS-9 & $\begin{array}{l}\text { ACGTCCAGTCGGAGCATCATCACCATCACCATCACCATCATCATACGAGCG } \\
\text { GACTGCAG }\end{array}$ & PCR Blenc E61-his 10-T62 forward \\
\hline OSMS-10 & $\begin{array}{l}\text { CTGCAGTCCGCTCGTATGATGATGGTGATGGTGATGGTGATGATGCTCCGA } \\
\text { CTGGACGT }\end{array}$ & PCR Blenc E61-his10-T62 reverse \\
\hline OSMS-11 & $\begin{array}{l}\text { TCCACGGGCTCGATCATCATCACCATCACCATCACCATCATCATGCGGCCG } \\
\text { GGATCGG }\end{array}$ & PCR Blenc D124-his 10-A125 forward \\
\hline OSMS-12 & $\begin{array}{l}\text { CCGATCCCGGCCGCATGATGATGGTGATGGTGATGGTGATGATGATCGAG } \\
\text { CCCGTGGA }\end{array}$ & PCR Blenc D124-his 10-A125 reverse \\
\hline OSMS-13 & $\begin{array}{l}\text { TCGTTCCCGGCAGCCATCATCACCATCACCATCACCATCATCATTCGAATGC } \\
\text { CGCAGT }\end{array}$ & PCR Blenc S135-his10-S136 forward \\
\hline OSMS-14 & $\begin{array}{l}\text { ACTGCGGCATTCGAATGATGATGGTGATGGTGATGGTGATGATGGCTGCC } \\
\text { GGGAACGA }\end{array}$ & PCR Blenc S135-his10-S136 reverse \\
\hline OSMS-21 & $\begin{array}{l}\text { GCGTGGCCGGCCGATATCTCAATGATGATGGTGATGGTGATGGTGATGAT } \\
\text { GGAACTTTAGAAGAATCAA }\end{array}$ & $\begin{array}{l}\text { PCR TmencH10 reverse for EcoRV site in } \\
\text { pDuet MCS2 }\end{array}$ \\
\hline OSMS-22 & GCGTGGCCGGCCGATATCTCAGAACTTTAGAAGAATCAA & $\begin{array}{l}\text { PCR Tmenc reverse for EcoRV site in pDuet } \\
\text { MCS2 }\end{array}$ \\
\hline OSMS-23 & $\begin{array}{l}\text { TGCTTTCAGACGAGCATCATCACCATCACCATCACCATCATCATAACGAAGT } \\
\text { GGTGAA }\end{array}$ & PCR Tmenc E64-his10-N65 forward \\
\hline OSMS-24 & $\begin{array}{l}\text { TTCACCACTTCGTTATGATGATGGTGATGGTGATGGTGATGATGCTCGTCT } \\
\text { GAAAGCA }\end{array}$ & PCR Tmenc E64-his10-N65 reverse \\
\hline OSMS-25 & $\begin{array}{l}\text { TCAGAGGATGTGAACATCATCACCATCACCATCACCATCATCATAAATCGG } \\
\text { GTGTIAA }\end{array}$ & PCR Tmenc E127-his10-K128 forward \\
\hline OSMS-26 & $\begin{array}{l}\text { TTAACACCCGATTTATGATGATGGTGATGGTGATGGTGATGATGTTCACAT } \\
\text { CCTCTGA }\end{array}$ & PCR Tmenc E127-his 10-K128 reverse \\
\hline OSMS-27 & $\begin{array}{l}\text { TाCTITCCTTCGAACATCATCACCATCACCATCACCATCATCATGAGAGGAA } \\
\text { AATCGA }\end{array}$ & PCR Tmenc E138-his10-E139 forward \\
\hline OSMS-28 & $\begin{array}{l}\text { TCGATTTTCCTCTCATGATGATGGTGATGGTGATGGTGATGATGTTCGAAG } \\
\text { GAAAGAA }\end{array}$ & PCR Tmenc E138-his10-E139 reverse \\
\hline OSMS-89 & GAATGGAGCCACCCGCAGTTCGAAAAGAAATCGGGTGTTAAAGGCCTT & PCR Tmenc E127-Strep-K128 forward \\
\hline OSMS-117 & TITCTTITCGAACTGCGGGTGGCTCCATTCACATCCTCTGAATATCA & PCR Tmenc E127-Strep-K128 reverse \\
\hline OSMS-112 & GAATGCACCAGCACCAGCGCGCCGTATTGCAAATCGGGTGTTAAAGGCCTT & PCR Tmenc E127-PepC7-K128 forward \\
\hline OSMS-120 & ATACGGCGCGCTGGTGCTGGTGCATTCACATCCTCTGAATATCA & PCR Tmenc E127-PepC7-K128 reveverse \\
\hline OSMS-114 & $\begin{array}{l}\text { GCGTGGCCGGCCGATATCTCACTTTTCGAACTGCGGGTGGCTCCAGAACTT } \\
\text { TAGAAGAATCAA }\end{array}$ & PCR Tmenc Strep EcorV reverse \\
\hline
\end{tabular}

${ }^{a_{T}}$ The DNA sequence is colored corresponding to the residue or peptide sequence described in characteristics.

Transmission Electron Microscopy (TEM). TEM measurements were performed using a Philips CM300ST-FEG transmission electron microscope. Each sample ( $5 \mu \mathrm{L})$ was applied to a Formvar carboncoated copper grid (Electron Microscopy Sciences). The samples were 


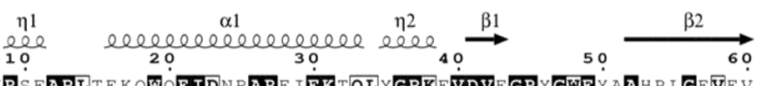

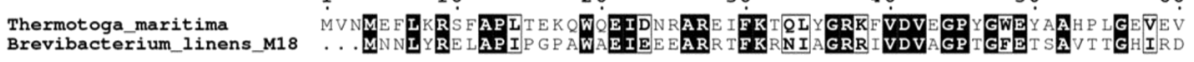

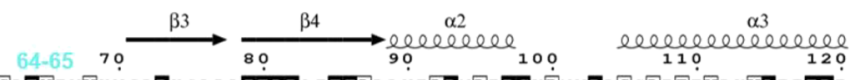

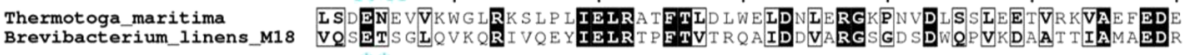

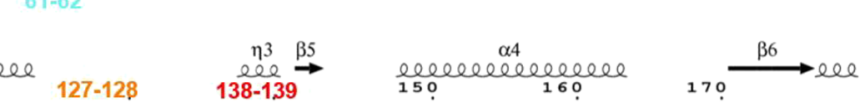

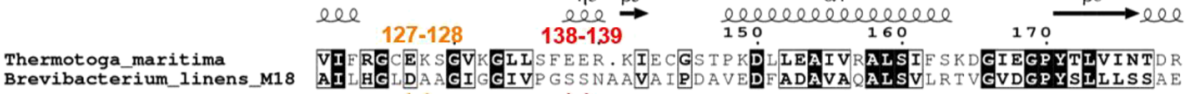
$\begin{array}{cc}* * & * * \\ 124-125 & 135-136\end{array}$

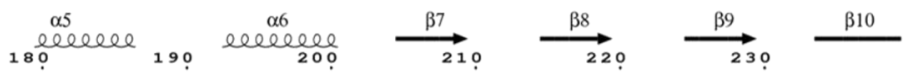

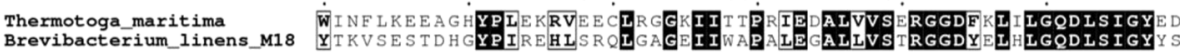

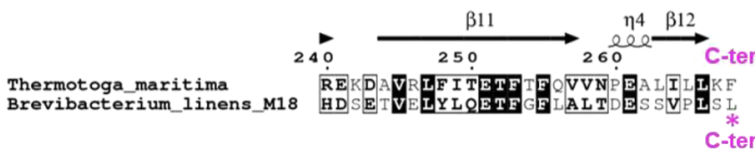

Figure 2. Alignment of Tm and $\mathrm{Bl}$ encapsulins with (in black) similar residues and (in boxes) the homologous substitution. The stars represent the similar residues between Blenc and Tmenc for the selection of the loop on Blenc.

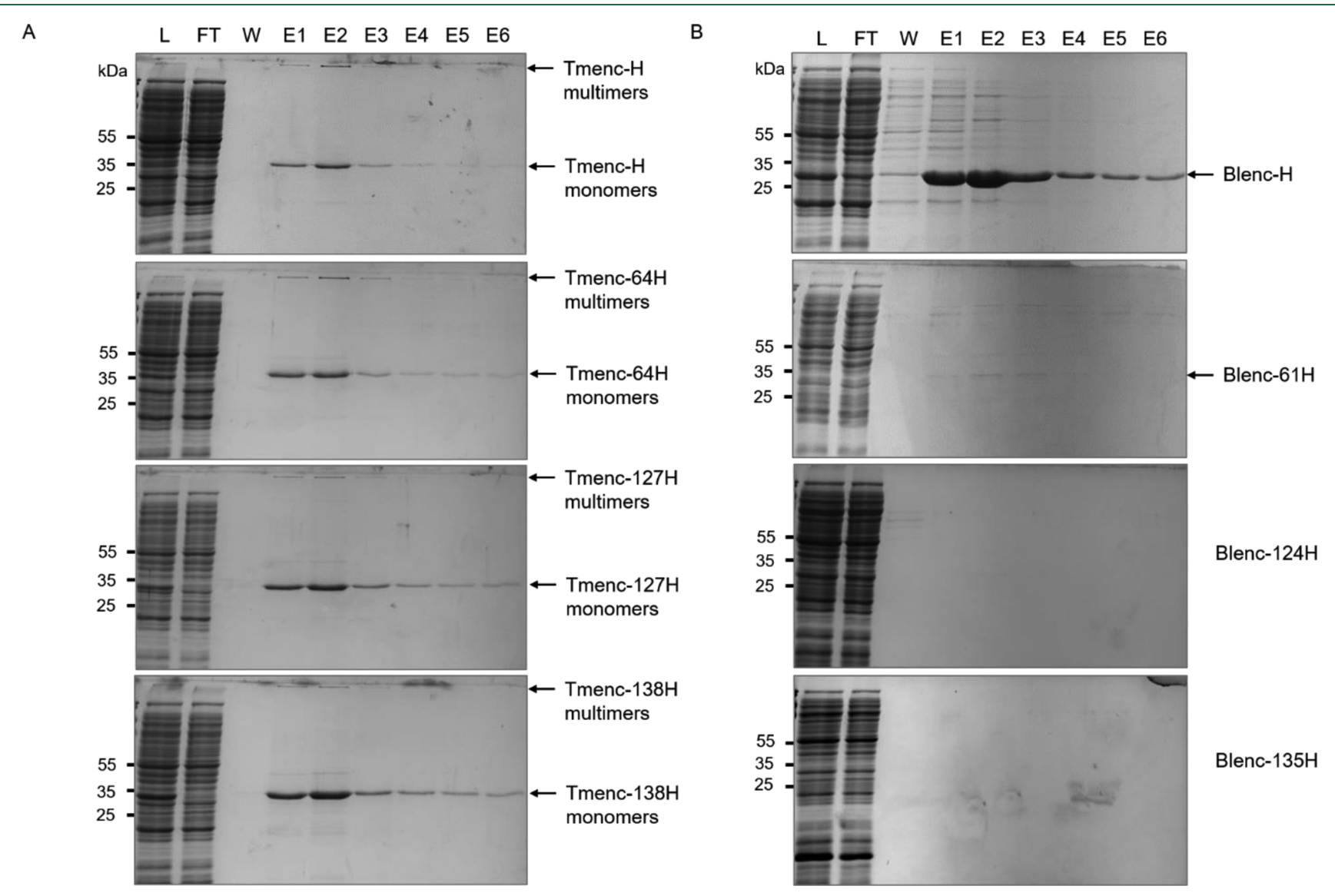

Figure 3. SDS-PAGE analysis of the purification of the different encapsulin variants by affinity chromatography on nickel columns. The fractions are analyzed by SDS-PAGE and stained by Coomassie blue. $\mathrm{L}=$ loading, $\mathrm{FT}=$ flow through, $\mathrm{W}=$ wash, and $\mathrm{E}=$ elution. Molecular weight markers (in $\mathrm{kDa}$ ) are indicated on the left. The different variants are indicated on the right of the arrows except for Blenc124H and $\mathrm{Blenc} 135 \mathrm{H}(\mathrm{B}$ bottom), where no protein is visible. (A) Analysis of Tmenc variants. (B) Analysis of Blenc variants.

incubated on the grid for $2 \mathrm{~min}$, and then, any excess buffer was removed with filter paper. The samples were negatively stained by applying $5 \mu \mathrm{L}$ of uranyl acetate $(1 \% \mathrm{w} / \mathrm{v})$ onto the grid and incubating for $40 \mathrm{~s}$. Any excess stain was removed, and the samples were left to dry 
A

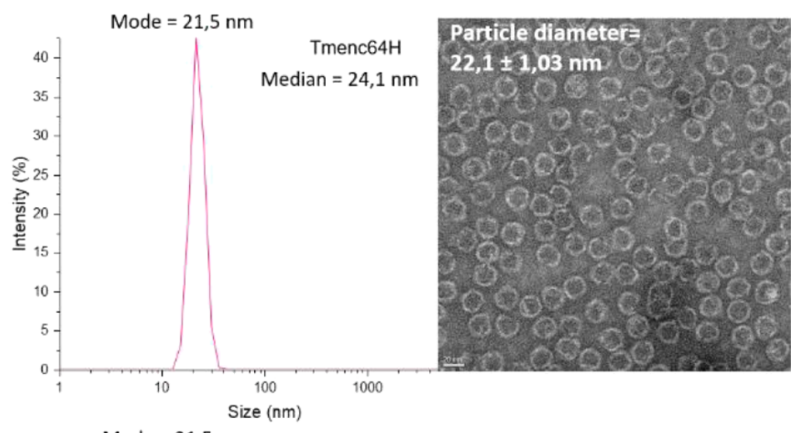

B

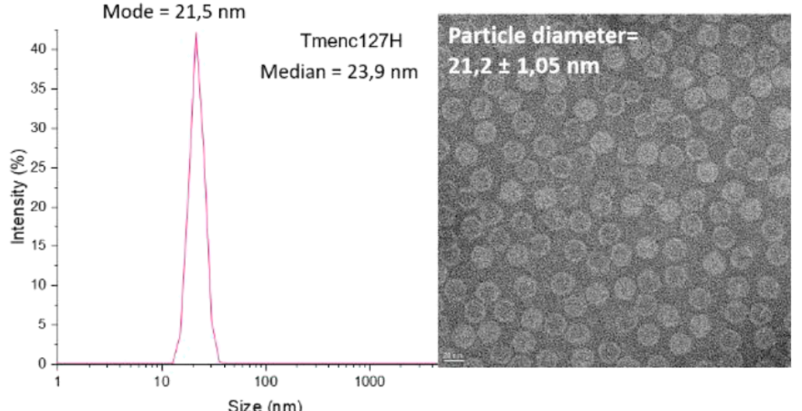

C

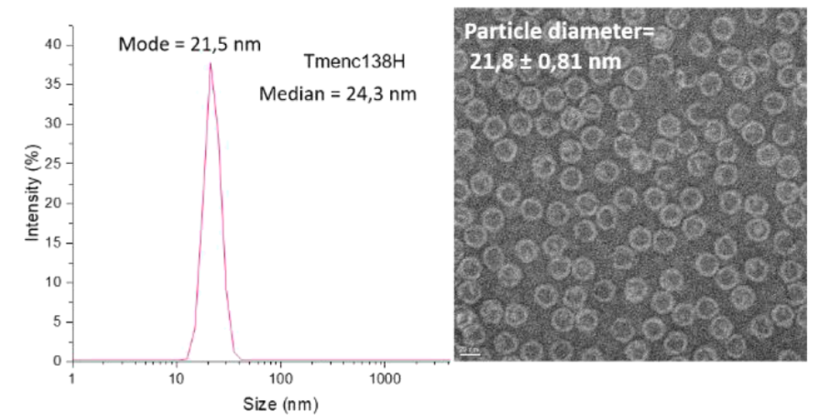

D

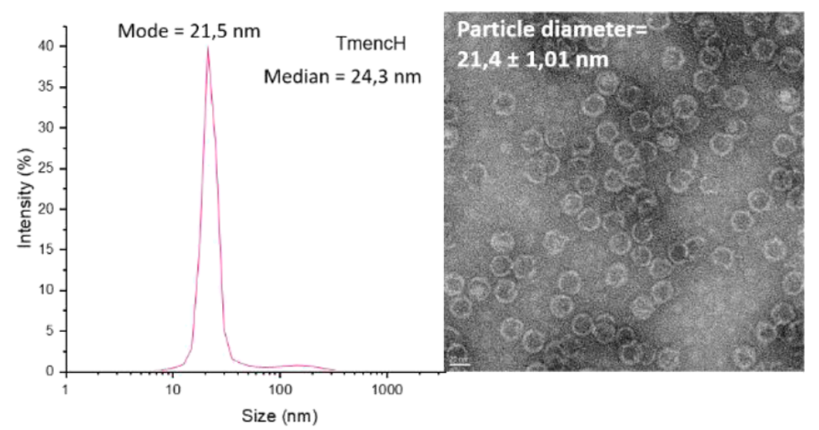

E

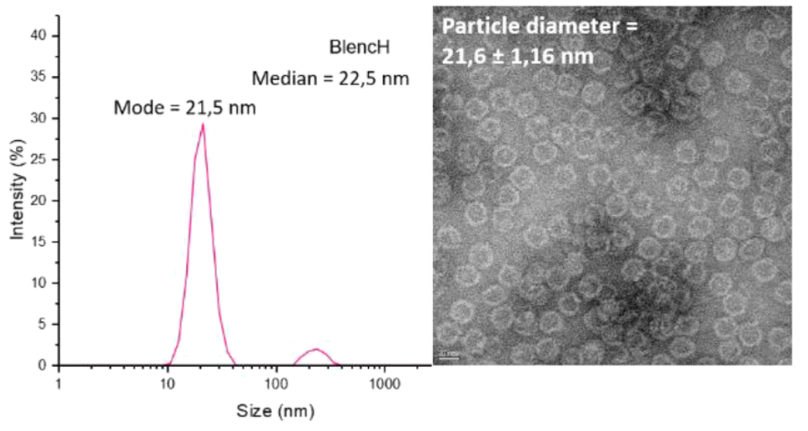

Figure 4. Size and morphological characterization of the Tmenc variants and BlencH. DLS-based size distributions (left) and negatively stained TEM images (right) of encapsulin particles for (A) Tmenc64H, (B) Tmenc127H, (C) Tmenc138H, (D) TmencH, and (E) BlencH. Mode and median size of the particles in DLS were determined by the software of the machine, and the average particle size form TEM was determined as described in the Experimental Section.

for $10 \mathrm{~min}$ before imaging. The size of encapsulin cages was determined by using ImageJ (http://imagej.nih.gov/ij/) averaging 30 measurements.

Dynamic Light Scattering (DLS). The hydrodynamic size distribution of the particles was determined using a Nanotrac Wave (Microtrac) particle analyzer. An average over 5 runs of $120 \mathrm{~s}$ each was used to determine the size deduced from the intensity distribution. The number distribution was displayed to visualize the major contribution to the size determination.

Cellular Uptake. bEND. 3 cells (ATCC) were seeded at $10 \times 10^{3}$ cells per well in a 96-well plate in the Dulbecco modified Eagles medium (DMEM), fetal bovine serum, penicillin-streptomycin (containing 10.000 units penicillin and $10 \mathrm{mg}$ of streptomycin $\mathrm{mL}^{-1}$ ). After $24 \mathrm{~h}$ incubation at $37{ }^{\circ} \mathrm{C}$ in a humidified $5 \% \mathrm{CO}_{2}$-containing atmosphere, TmPepc7-sfGFP and TmStrep-sfGFP were diluted to $50 \mathrm{nM}$ in DMEM and added to the cells. The particles were incubated for $4 \mathrm{~h}$. Subsequently, the cells were washed with phosphate buffered saline (PBS, pH 7.4) with 4\% paraformaldehyde and stained with 4,6diamidino-2-phenylindole dihydrochloride (DAPI) and wheat germ agglutinin (WGA) staining. The cellular uptake was analyzed by confocal fluorescence microscopy using a Zeiss Confocal LSM880 with $20 \times$ objective. The laser and filters used were ex $405 / \mathrm{em} 454$ for DAPI/ WGA and ex 488/em 548 for GFP.

\section{RESULTS AND DISCUSSION}

Selection of Loops on Tmenc and Blenc and Variant Construction. To construct encapsulin variants, we first selected promising candidates for surface modification based on the resolved encapsulin structure of Tmenc described by Sutter and co-workers ${ }^{15}$ using the PyMol software (The PyMOL Molecular Graphics System, Version 2.1 Schrödinger, LLC). ${ }^{25}$ Following this approach, loops at positions 64, 127, and 138 and the C-terminus of Tmenc were investigated (Figure 1). As modifications in the loop at position 138 and the C-terminus were already characterized by Moon and co-workers, ${ }^{19}$ we decided to use position 138 as a benchmark for our experiments reproducing their results. In addition, while Moon et al. could not purify the variant with a modified C-terminus, we investigated encapsulin purification using a longer $\mathrm{His}_{10}$-tag instead of $\mathrm{His}_{6}$. The complete cage of Tmenc is represented in Figure $1 \mathrm{~A}$ with a single monomer highlighted in green. Figure $1 \mathrm{~B}$ shows a monomer with the designed modifications, and using a representation of a double pentamer, Figure $1 \mathrm{C}$ highlights the exposed position of the chosen residues. As the atomic structure of Blenc is unavailable so far, we proceeded by homology with Tmenc. Following a sequence alignment procedure using the ENDscript server, ${ }^{26}$ we selected the corresponding residues of Blenc, which are residues 61, 124, and 135 and the C-terminus 

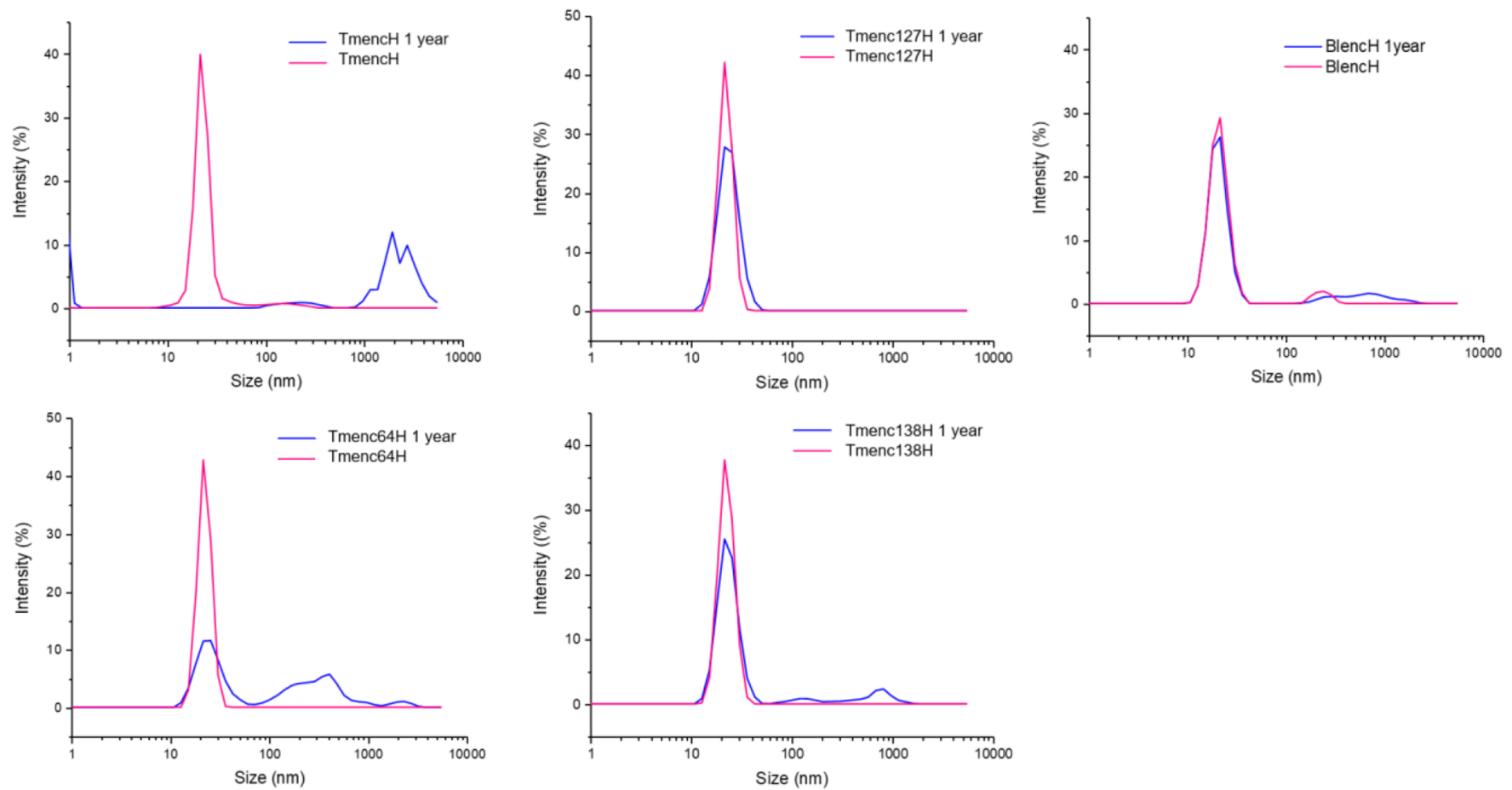

Figure 5. Stability study of different encapsulin variants by DLS. Size distributions of Tmenc64H, Tmenc127H, Tmenc138H, TmencH, and BlencH after 5 days (pink line) and 1 year (blue line).

(Figure 2). Next, we genetically inserted 10 histidines between each set of highlighted amino acids.

Purification of the Encapsulins. The variants were produced and assembled in bacteria. The soluble fraction was extracted and purified by affinity chromatography on NickelNTA columns. All the variants of Tmenc were purified and found in the elution fraction with a molecular weight of $32 \mathrm{kDa}$ (Figure 3A), which implies that the new variants are stable and the His-tag is exposed on the surface. Note that multimers of Tmenc were observed by SDS-PAGE, implying that a part of the Tmenc protein cages resists denaturation during sample preparation (heating and SDS treatment). Concerning Blenc, while BlencH (Blenc with 10 histidines in the C-terminal domain) is correctly purified and found in the elution fractions with a molecular weight of $30 \mathrm{kDa}$ (Figure $3 \mathrm{~B}$ top), this is not the case for the other variants of Blenc. Blenc $61 \mathrm{H}$ is purified but at a lower yield compared to BlencH, and for the variants Blenc124H and Blenc135H, no proteins are present in the elution fractions. To clarify what happens with the latter variants and why they could not be purified, we tested both their production and stability in bacteria. Thereby, we followed the production of Blenc124H and Blenc135H with BlencH as positive control (Figure S1). This revealed that all the variants are produced, implying that the problem is not the protein production, but presumably the purification is. Although the stability of variants 124 and 135 differs compared to variant BlencH, proteins are still present $21 \mathrm{~h}$ after production. Consequently, the nonattachment to the nickel column could result from either protein aggregation, forming inclusion bodies, or from the tag being hidden. The latter would suggest that the chosen loops are not exposed on the surface, or alternatively that the insertion of the His-tag involves a conformational change, which buries the loop with the tag.

Structure and Size Characterization of the Encapsulins. After obtaining all the variants of Tmenc and $\mathrm{BlencH}$, we performed a second purification step by size exclusion chromatography (Figure S2). The other Blenc variants could not be isolated, and the yield for Blenc61H was too low for this second purification step. Using a Sepharose 6 10/300 column, the native encapsulin is found at an elution volume of $V \sim 12$ mL. ${ }^{18}$ Calibration of the column yields that $V=12 \mathrm{~mL}$ corresponds to a size of approximately $2000 \mathrm{kDa}$, being close to the calculated encapsulin mass $(1932 \mathrm{kDa})$. To further analyze the size and morphology of the designed encapsulins, we used DLS and TEM (Figure 4). The determined cage diameter from DLS measurements is $D=24 \mathrm{~nm}$, while from TEM image analysis, the mean diameter is found to be $D=21.5 \mathrm{~nm}$. This difference with the DLS median value can be explained considering the following: for TEM samples, the grid preparation could lead to a "drying effect" resulting in smaller particles compared to the solvated ones. Most importantly, all the studied variants have a size close to the one structurally determined by Sutter et al. and have a spherical shape similar to the wild-type encapsulin observed in previous studies. ${ }^{15,18,19}$ Note that from the DLS data (Figure 4D,E), we can see that the particles can cluster to form aggregates of a much larger size $(200-400 \mathrm{~nm})$. This effect is, however, negligible, as revealed by the number distribution obtained from DLS measurements showing that the majority of the population is in the $21.5 \mathrm{~nm}$ peak (Figure S3).

Buffer Optimization To Increase Encapsulin Stability and Avoid Protein Precipitation. Buffers used in previous studies, such as phosphate buffers ${ }^{19,21}$ and Tris buffers with $\mathrm{NH}_{4} \mathrm{Cl}-\mathrm{MgCl}_{2}$ or $\mathrm{NaCl}$ complemented with $1 \mathrm{mM} \beta$ mercaptoethanol, ${ }^{17}$ resulted in precipitation of proteins after 1-3 days or during handling (Figure S4). By changing the buffer composition to $50 \mathrm{mM}$ Hepes buffer, $150 \mathrm{mM} \mathrm{NaCl}$ with 15 $\mathrm{mM} \beta$-mercaptoethanol, we obtained stable particle solutions for all variants when stored at $4{ }^{\circ} \mathrm{C}$. Every solution was stable for at least 5 days, and the protein material could be recovered after 


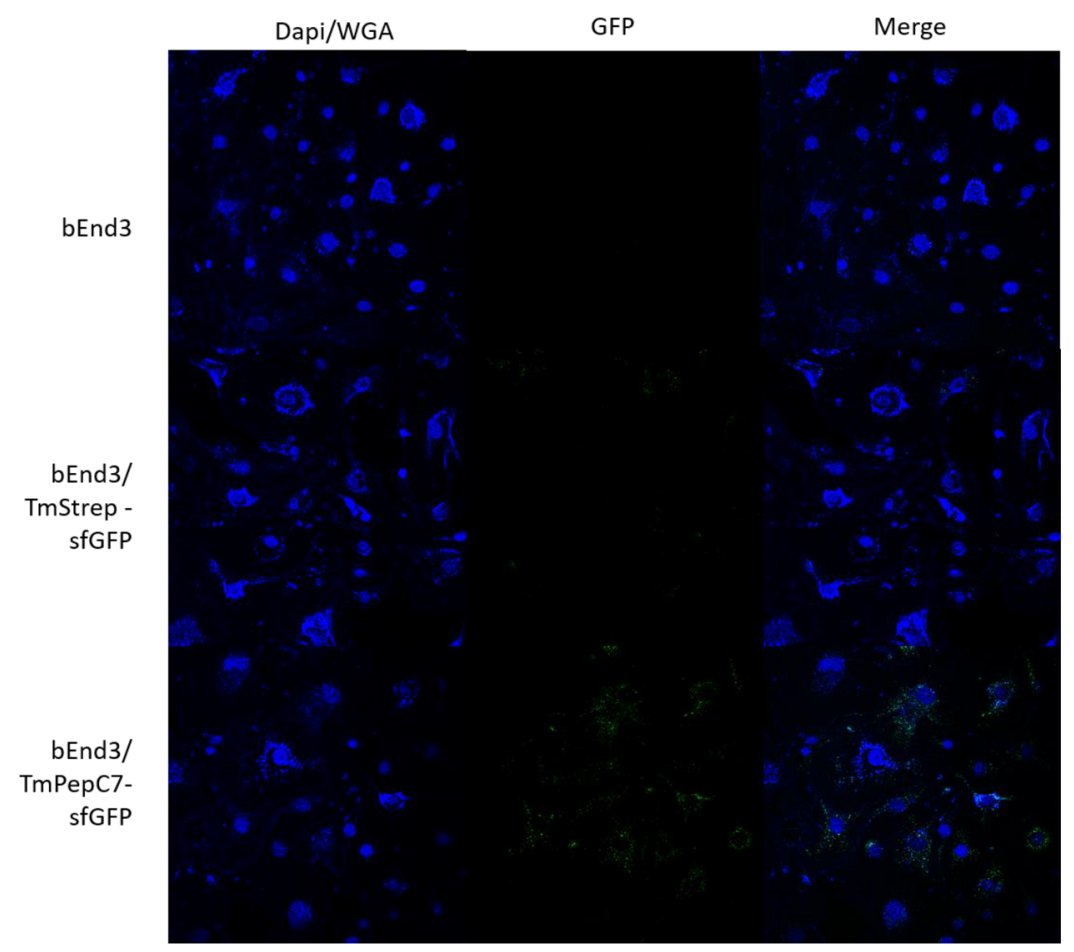

Figure 6. Tmenc uptake by bEnd.3 cells. Confocal fluorescence microscopy images with (in the first row) the cell untreated, (in the second row) the cells treated with $50 \mathrm{nM} \mathrm{Tm} 127 \mathrm{strep} / \mathrm{sfGFP}$, and (in the third row) the cells treated with $50 \mathrm{nM} \mathrm{Tm} 127 \mathrm{PepC} 7$-Cstrep/sfGFP. The first column shows the DAPI (nuclei) and WGA (membranes) staining, the second column shows the GFP emission, and the third shows the merge of these two channels.

Amicon concentration (Figure 4). The size of the cages was checked by DLS after 1 year of storage yielding different stabilities depending on the variant (Figure 5). The variants Tmenc127H, Tmenc138H, and BlencH are stable after 1 year of storage, while Tmenc64H showed partial aggregation. The encapsulin with the C-terminal modification ( $\mathrm{TmencH}$ ) completely aggregated over this time frame. The number distribution shows that for all variants, except $\mathrm{TmencH}$, the majority of the population still forms a cage of $D=24 \mathrm{~nm}$ (Figure S5). Note that as the same $\mathrm{His}_{10}$-tag was inserted in all designed encapsulins, it implies that the difference in stability originates from the position of the modification and not from the nature of the modification itself.

Furthermore, we noticed that by using our protocol, we get a higher purification yield compared to the study of Lee and coworkers. $^{23}$ From $1 \mathrm{~L}$ of culture, we obtained between 1 and 2 $\mathrm{mg} / \mathrm{mL}$ of purified protein, while Lee and co-workers reported a yield of $0.039 \mathrm{mg} / \mathrm{mL}$ from $0.8 \mathrm{~L}$ of culture, a net 20 -fold increase. This observation can be, tentatively, explained by an increased yield for the affinity chromatography; however, we changed various other parameters, such as the buffer, the vector, and the combined purification method in comparison to the work by Lee and co-workers. An in-depth investigation of the parameters, which lead to such a noticeable increase of the cage production yield, is beyond the scope of the present work but will be addressed in a further study.

Functionalization with the PepC7 Targeting Peptide. To demonstrate the use of functionalized encapsulins in a targeting application, the peptide PepC7 was added in position 127 of Tmenc. In addition, to keep the advantage of affinity chromatography purification, a Strep-tag II was added at the Cterminus. This peptide PepC7 (CTSTSAPYC) is identified by phage display as a brain-targeting peptide. ${ }^{27,28}$ Drug delivery to the brain is a big challenge, due to the difficulty of getting through the blood-brain barrier (BBB). One of the emergent strategies is to employ $\mathrm{BBB}$ shuttle peptides that can be combined with nanoscale drug delivery carriers. ${ }^{29-31}$

To follow the encapsulin uptake by the brain cells, a fluorescent protein, super-folder GFP (sfGFP), was fused with the $\mathrm{E}$ extension ( $\mathrm{C}$-terminal sequence) of the native cargo, that is, ferredoxin-like protein (Flp), to be encapsulated in the cage. ${ }^{15}$ The encapsulin Tm127PepC7/sfGFP was purified with a StrepTactin column followed by size exclusion chromatography, similar to the purification process of the Tmenc histidine variants (Figure S6B); this is an important result, as it demonstrates that position 127 and the C-terminus can be modified simultaneously.

The uptake was tested on brain endothelial cells (bEnd.3 cells). As a control, a cage with only Strep Tags was engineered, loaded with sfGFP, and purified (Figure S6A). One of the advantages of using Tmenc as the targeting delivery system is that this protein cage is virtually not internalized when it does not have specific surface modification, as already observed in previous studies with different cell lines. ${ }^{32}$ Consistently, a similar behavior is observed here with the bEnd. 3 cell line. In Figure 6, the uptake of TmPepC7/sfGFP by the cells is evident from the GFP emission in the bottom row, while the bEnd.3 cells and the control TmStrep/sfGFP do not display the green spot surrounding the cell nuclei. This shows that encapsulins modified with PepC7 targeting peptides can enter brain endothelial cells.

\section{CONCLUSIONS}

This study reports the successful insertion of functional loops at two new positions on the surface of the Tm encapsulin, that is, after residues 64 and 127. It also shows the successful modification of the $\mathrm{C}$-terminus of the $\mathrm{Bl}$ encapsulin, which is exposed and accessible on the surface. Modification of the C- 
terminus of Tmenc was also investigated, and we show that compared to the study of Moon and co-workers, ${ }^{19}$ an increase of the size of the histidine tag from 6 to 10 residues allows the purification by immobilized metal affinity chromatography. Consequently, this position can be used for further applications by adding a linker between the inserted peptide and the encapsulin.

As the structure of Blenc is not available, we used a sequence and structure homology approach between Tmenc and Blenc to investigate modifiable loops on Blenc. However, functional Blenc variants could not be isolated, implying that this approach is not feasible in the studied examples: the structure is essential for an efficient investigation of new modifiable positions.

Using our protocol, we were able to considerably increase the short-term stability of encapsulins, and we showed that some samples can have long-term stability up to a year. This study further demonstrates that even if the integrity of the cage is kept, modifications on the surface affect the structure and induce differences in long-term stability.

The utilization of encapsulins for medical applications is highly promising, thanks to their large set of advantages, resulting from their small size and their biocompatibility. Note that further studies are yet required to fully evaluate the encapsulin immune reaction. Previous studies already showed how encapsulins can be employed for liver targeting, vaccine development, and imaging or as nanoreactors. ${ }^{7,21,32-34}$ Therefore, it is crucial to deepen our knowledge about modification of encapsulins and to optimize their production and usability. Hence, this study paves the way for the development of improved encapsulin engineering and production. It should enable a wide range of further studies investigating multivalency, targeting, and delivery for multivaccine or multitargeting applications. Indeed, further studies are ongoing to create well-defined modified surfaces by having 60 functional groups when every protein subunit has a single modification and 240 functional groups when each subunit has 4 (different) modifications. So far, in this study, we demonstrate the possibility to have two positions modified simultaneously, position 127 and the C-terminus, leading to a protein nanocage with 120 functional groups.

Finally, we demonstrated the ability of targeting the BBB with encapsulins. Future investigations using different $B B B$ shuttle peptides and $\mathrm{BBB}$ transport models are ongoing to investigate the utilization of encapsulins for drug delivery to the brain.

\section{ASSOCIATED CONTENT}

\section{SI Supporting Information}

The Supporting Information is available free of charge at https://pubs.acs.org/doi/10.1021/acs.biomac.1c01156.

(Figure S1) Production and stability of the variants BLenc124H and Blenc135H in bacteria; (Figure S2) purification of the different encapsulin variant by size exclusion chromatograph; (Figure S3) DLS measurement of encapsulin variants using number distribution; (Figure S4) precipitation of Tmenc64H in a dialysis bag; (Figure S5) encapsulin stability analysis using DLS measurements with number distribution; and (Figure S6) purification of Tm127strep/sfGFP and Tm127PepC7/sfGFP by size exclusion chromatography (PDF)

\section{AUTHOR INFORMATION}

\section{Corresponding Authors}

Sandra Michel-Souzy - Department of Molecules and Materials, MESA + Institute for Nanotechnology, University of Twente, 7500 AE Enschede, The Netherlands;

Email: s.s.m.c.michel@utwente.nl

Jeroen J. L. M. Cornelissen - Department of Molecules and Materials, MESA+ Institute for Nanotechnology, University of Twente, 7500 AE Enschede, The Netherlands; (1) orcid.org/ 0000-0002-9728-5043; Email: J.J.L.M.Cornelissen@ utwente.nl

\section{Authors}

Naomi M. Hamelmann - Department of Molecules and Materials, MESA+ Institute for Nanotechnology, University of Twente, 7500 AE Enschede, The Netherlands; 이이.org/ 0000-0002-7126-4818

Sara Zarzuela-Pura - Department of Molecules and Materials, MESA+ Institute for Nanotechnology, University of Twente, 7500 AE Enschede, The Netherlands

Jos M. J. Paulusse - Department of Molecules and Materials, MESA+ Institute for Nanotechnology, University of Twente, 7500 AE Enschede, The Netherlands; 이이. orcid.org/00000003-0697-7202

Complete contact information is available at:

https://pubs.acs.org/10.1021/acs.biomac.1c01156

\section{Funding}

This work was supported by European Research Council (ERC Consolidator Grant, Protcage \#616907).

\section{Notes}

The authors declare no competing financial interest.

\section{ACKNOWLEDGMENTS}

We thank Dr. E. G. Keim, (MESA+ Institute for Nanotechnology, University of Twente) for assistance with TEM measurements. We thank Dr. Eric Cascales for the sfGFP gene. We thank Dr. Mathieu Souzy, Dr. Dorothee Wasserberg, and Jessica Nettofrez for proofreading the manuscript.

\section{REFERENCES}

(1) Williams, D. F. On the mechanisms of biocompatibility. Biomaterials 2008, 29, 2941-2953.

(2) Allen, T. M.; Cullis, P. R. Liposomal drug delivery systems: From concept to clinical applications. Adv. Drug Delivery Rev. 2013, 65, 3648.

(3) Pinelli, F.; Ortolà, Ó. F.; Makvandi, P.; Perale, G.; Filippo, R. In vivo drug delivery applications of nanogels : a review. NANO 2020, 15, $2707-2727$.

(4) Hwang, D.; Ramsey, J. D.; Kabanov, A. V. Polymeric micelles for the delivery of poorly soluble drugs: From nanoformulation to clinical approval. Adv. Drug Delivery Rev. 2020, 156, 80-118.

(5) Steinmetz, N. F.; Lim, S.; Sainsbury, F. Protein cages and virus-like particles: From fundamental insight to biomimetic therapeutics. Biomater. Sci. 2020, 8, 2771-2777.

(6) Rohovie, M. J.; Nagasawa, M.; Swartz, J. R. Virus-like particles: Next-generation nanoparticles for targeted therapeutic delivery. Bioeng. Transl. Med. 2017, 2, 43-57.

(7) Sigmund, F.; Pettinger, S.; Kube, M.; Schneider, F.; Schifferer, M.; Schneider, S.; Efremova, M. V.; Pujol-Martí, J.; Aichler, M.; Walch, A.; Misgeld, T.; DIetz, H.; Westmeyer, G. G. Iron-Sequestering Nanocompartments as Multiplexed Electron Microscopy Gene Reporters. ACS Nano 2019, 13, 8114-8123. 
(8) Charlton Hume, H. K.; Vidigal, J.; Carrondo, M. J. T.; Middelberg, A. P. J.; Roldão, A.; Lua, L. H. L. Synthetic biology for bioengineering virus-like particle vaccines. Biotechnol. Bioeng. 2019, 116, 919-935.

(9) Choi, B.; Kim, H.; Choi, H.; Kang, S. Protein Cage Nanoparticles as Delivery Nanoplatforms. Adv. Exp. Med. Biol. 2018, 1064, 27-43.

(10) Lee, E. J.; Lee, N. K.; Kim, I. S. Bioengineered protein-based nanocage for drug delivery. Adv. Drug Delivery Rev. 2016, 106, 157171.

(11) Naahidi, S.; Jafari, M.; Edalat, F.; Raymond, K.; Khademhosseini, A.; Chen, P. Biocompatibility of engineered nanoparticles for drug delivery. J. Controlled Release 2013, 166, 182-194.

(12) Jones, J. A.; Giessen, T. W. Advances in encapsulin nanocompartment biology and engineering. Biotechnol. Bioeng. 2020, 118, 491-505.

(13) McHugh, C. A.; Fontana, J.; Nemecek, D.; Cheng, N.; Aksyuk, A. A.; Heymann, J. B.; Winkler, D. C.; Lam, A. S.; Wall, J. S.; Steven, A. C.; Hoiczyk, E. A virus capsid-like nanocompartment that stores iron and protects bacteria from oxidative stress. EMBO J. 2014, 33, 1-16.

(14) Akita, F.; Chong, K. T.; Tanaka, H.; Yamashita, E.; Miyazaki, N.; Nakaishi, Y.; Suzuki, M.; Namba, K.; Ono, Y.; Tsukihara, T.; Nakagawa, A. The Crystal Structure of a Virus-like Particle from the Hyperthermophilic Archaeon Pyrococcus furiosus Provides Insight into the Evolution of Viruses. J. Mol. Biol. 2007, 368, 1469-1483.

(15) Sutter, M.; Boehringer, D.; Gutmann, S.; Günther, S.; Prangishvili, D.; Loessner, M. J.; Stetter, K. O.; Weber-Ban, E.; Ban, N. Structural basis of enzyme encapsulation into a bacterial nanocompartment. Nat. Struct. Mol. Biol. 2008, 15, 939-947.

(16) Giessen, T.; Encapsulins, W. Microbial nanocompartments with applications in biomedicine, nanobiotechnology and materials science. Curr. Opin. Chem. Biol. 2016, 34, 1-10.

(17) Rurup, W. F.; Snijder, J.; Koay, M. S. T.; Heck, A. J. R.; Cornelissen, J. J. L. M. Self-sorting of foreign proteins in a bacterial nanocompartment. J. Am. Chem. Soc. 2014, 136, 3828-3832.

(18) Putri, R. M.; Allende-Ballestero, C.; Luque, D.; Klem, R.; Rousou, K. A.; Liu, A.; Traulsen, C. H. H.; Rurup, W. F.; Koay, M. S. T.; Castón, J. R.; Cornelissen, J. J. L. M. Structural Characterization of Native and Modified Encapsulins as Nanoplatforms for in Vitro Catalysis and Cellular Uptake. ACS Nano 2017, 11, 12796-12804.

(19) Moon, H.; Lee, J.; Min, J.; Kang, S. Developing genetically engineered encapsulin protein cage nanoparticles as a targeted delivery nanoplatform. Biomacromolecules 2014, 15, 3794-3801.

(20) Choi, B.; Moon, H.; Hong, S. J.; Shin, C.; Do, Y.; Ryu, S.; Kang, S. Effective Delivery of Antigen-Encapsulin Nanoparticle Fusions to Dendritic Cells Leads to Antigen-Specific Cytotoxic T Cell Activation and Tumor Rejection. ACS Nano 2016, 10, 7339-7350.

(21) Lagoutte, P.; Mignon, C.; Stadthagen, G.; Potisopon, S.; Donnat, S.; Mast, J.; Lugari, A.; Werle, B. Simultaneous surface display and cargo loading of encapsulin nanocompartments and their use for rational vaccine design. Vaccine 2018, 36, 3622-3628.

(22) Bae, Y.; Kim, G. J.; Kim, H.; Park, S. G.; Jung, H. S.; Kang, S. Engineering Tunable Dual Functional Protein Cage Nanoparticles Using Bacterial Superglue. Biomacromolecules 2018, 19, 2896-2904.

(23) Lee, T.; Carpenter, T. S.; D’haeseleer, P.; Savage, D. F.; Yung, M. C. Encapsulin carrier proteins for enhanced expression of antimicrobial peptides. Biotechnol. Bioeng. 2019, 117, 603-613.

(24) Jeong, J. Y.; Yim, H. S.; Ryu, J. Y.; Lee, H. S.; Lee, J. H.; Seen, D. S.; Kang, S. G. One-step sequence- and ligation-independent cloning as a rapid and versatile cloning method for functional genomics Studies. Appl. Environ. Microbiol. 2012, 78, 5440-5443.

(25) The PyMOL Molecular Graphics System, Version 2.0 Schrödinger, LLC.

(26) Robert, X.; Gouet, P. Deciphering key features in protein structures with the new ENDscript server. Nucleic Acids Res. 2014, 42, $320-324$.

(27) Li, J.; Zhang, Q.; Pang, Z.; Wang, Y.; Liu, Q.; Guo, L.; Jiang, X. Identification of peptide sequences that target to the brain using in vivo phage display. Amino Acids 2012, 42, 2373-2381.

(28) Díaz-Perlas, C.; Sánchez-Navarro, M.; Oller-Salvia, B.; Moreno, M.; Teixidó, M.; Giralt, E. Phage display as a tool to discover blood- brain barrier (BBB)-shuttle peptides: panning against a human $\mathrm{BBB}$ cellular model. Biopolymers 2017, 108, 1-13.

(29) Oller-Salvia, B.; Sánchez-Navarro, M.; Giralt, E.; Teixidó, M. Blood-brain barrier shuttle peptides: An emerging paradigm for brain delivery. Chem. Soc. Rev. 2016, 45, 4690-4707.

(30) Dong, X. Current strategies for brain drug delivery. Theranostics 2018, 8, 1481-1493.

(31) Alyautdin, R.; Khalin, I.; Nafeeza, M. I.; Haron, M. H.; Kuznetsov, D. Nanoscale drug delivery systems and the blood-brain barrier. Int. J. Nanomed. 2014, 9, 795-811.

(32) Moon, H.; Lee, J.; Kim, H.; Heo, S.; Min, J.; Kang, S. Genetically engineering encapsulin protein cage nanoparticle as a SCC-7 cell targeting optical nanoprobe. Biomater. Res. 2014, 18, 1-7.

(33) Liu, A.; Traulsen, C. H. H.; Cornelissen, J. J. L. M. Nitroarene Reduction by a Virus Protein Cage Based Nanoreactor. ACS Catal. 2016, 6, 3084-3091.

(34) Gabashvili, A. N.; Chmelyuk, N. S.; Efremova, M. V.; Malinovskaya, J. A.; Semkina, A. S.; Abakumov, M. A. Encapsulinsbacterial protein nanocompartments: Structure, properties, and application. Biomolecules 2020, 10, 1-12. 